Special Article

\title{
Family therapy
}

\author{
Stuart Lieberman
}

Department of Mental Health Sciences, St George's Hospital Medical School, London SW17 0RE, UK

\begin{abstract}
Summary: The discipline of family therapy, one of the psychotherapies, is defined and illustrated clinically in this article using case material. References are provided which allow further reading about family systems medicine.
\end{abstract}

\section{Introduction}

Family therapy arose out of the need to enlarge the context of illness to include the understanding of how important relationships can injure or cure individuals. Links between the family system and the biology of the individual were discussed as early as 1939 by Pickle. ${ }^{1}$ Connections between biology and the family system have developed into the current concept of multifactorial aetiology which presumes that the biology of a person is influenced by genes, environment and behaviour. Causation and treatment can only be addressed by looking at the ecology of an organism in conjunction with the innards of the biological systems.

Family therapy is the treatment component of the philosophy that extends concepts of illness, defining it to include a person's nodal involvement in his or her kinship network. Family therapy is a form of psychotherapy, the treatment of illness by psychological means. Family therapy differs from other psychotherapies in that the kinship network is the system which is primarily treated. Stress placed upon the kinship network by developmental, life-cycle changes such as births, marriages, ageing or 'leaving home' issues is to be alleviated through the therapy. Stress placed upon the kinship network by illness, unexpected death, divorce or other extraordinary family events is treated through adjustments in the relationships, organization or structure of the family kinship network. Specifically, a family therapist aims to facilitate, educate or intervene actively in relationships between members of the family kinship in order to help them adjust to changes that have occurred within themselves, in society or in relationships which have become too rigid to allow for normal developments in the healthy functioning of the family.

Correspondence: Stuart Lieberman, M.D., F.R.C.Psych. Accepted: 20 June 1992
The observation of family interactions in the 1950 s and $1960 \mathrm{~s}^{2}$ led to the development of family therapy from the 1970 s to the present decade. Family therapists continue to struggle with the consequences of family-biological system interactions both in the area of health care processes and for the course and outcome of illness. ${ }^{3}$

\section{The family therapist at work}

The family therapist takes a very different sort of history from that required by a biologist or individual psychotherapist. Linear causality is enhanced by an interest in circular and spiralling processes. Habitual patterns of behaviour are an important subject for scrutiny. 'Who says what in what circumstances?' becomes as important as 'Where does it hurt?' Are there historically repetitive sequences of interaction that assume a rigid pattern in the present? Was the pattern inscribed in myth, legend, or script in previous generations? A new language has been developing necessarily to enable communication of the substance of observable family interaction.

The therapy concentrates on the problem presented in diverse ways. Some family therapists primarily intervene by changing structure; others examine and alter problem-maintaining behaviours; some therapists change future histories by reworking past events and other rely on the change in meaning of each family member's cognitions to engender changes in relationships and behaviour.

Therapists may actively intervene in the therapy room, the 'operating theatre', when family members display and repeat destructive sequences of behaviour in the room. 'My son is a lazy good-for-nothing layabout' repeated one father about his physically disabled son. These critical comments inexorably led to his wife defending her son while he retreated further into sullen defiance. 
But the therapist interrupts this sequence, coaching father into different ways of helping his son get up in the morning rather than forcefully criticizing him. This small change is a difference in the habitual pattern which, if maintained, can lead to greater difference in future, solving the presenting complaint.

Therapists may concentrate on the problem presented and identify the attempts made by each member of the kinship network and other helping professionals to solve the problem since no improvement has occurred, the attempts to solve the original problem can become the new problem as well-meaning attempts to 'try harder' to solve a problem become the ecology of an environment of worsening symptoms so that a downward spiral of functioning leads to severe, intractable symptoms.

During one family therapy session I explained to two ageing parents and the patient's older sister that the seventeen year course of treatment by general practitioners, psychiatrists, psychologists and behaviour therapists had aimed at the wrong goal. The concept of the family and the helping profession were based on the belief that the patient, a 33 year old man with depressive, anxious obsessional symptoms and suicidal thoughts was ill. His illness had been characterized by the aforementioned symptoms. Various diagnoses had been entertained: anxiety state, mixed depression, obsessive-compulsive neurosis and so on. Seventeen years of treatment had resulted in the use of a plethora of antidepressants, tranquillizers, neuroleptics and finally led to the suggestion by one psychiatrist that a stereotactic leucotomy might be necessary.

I offered an alternative explanation. At the age of seventeen, a young insecure teenage boy sought help for disturbing feelings, thoughts and worries. A kindly, well-meaning doctor offered a medical explanation backed up by medication. A pattern developed in which the boy considered his worries about growing up and his failures in life as an alien and intrusive illness to be treated medically. Failure of treatment raised his anxiety leading to greater worries and symptoms. 'I must be a very bad case.' His parents couldn't help him by directing him into better occupation of his talents and skill. It was an illness for the doctor to handle. I explained the spiralling nature of the process in which patient, doctor, family and friend were caught up. For example, the father now spent hours on weekends allowing his son to ruminate incessantly upon his symptoms. Over time his life had contracted from that of a working, sport-loving boy on the cusp of manhood to a dependent demoralized adult. My explanation to the family differed. His feelings and thoughts were mistakenly diagnosed as symptoms. He was in need of help to grow up, not in need of a cure of his illness.

The family understood. They returned to the next session sobered and disturbed by this new reality: their 33 year old son was not ill; he needed to mature. His 'symptoms' were a creation maintained and enhanced yearly by attempts at treatment. A successful treatment of intractable $\overrightarrow{\vec{N}}$ hiccups ${ }^{4}$ reports a similar process in which the family and medical staff were able to reverse the symptoms through family systems therapy.

Other family therapists will try to change the way in which family members understand events in their life. They talk to families about their life stories, their scripts, their myths and legends. They will $\vec{\circ}$ explore and try to make new stories which better $\overrightarrow{\vec{\omega}}$ explain the family and its current dilemma. This story telling can be a reframing of the present $D$ concepts of illness or family relationships. It can be thought of as positively connoting negative viewpoints of family members about one another. One Irish couple who attended for marital therapy following the husband's myocardial infarct were astounded and astonished when I explained my view of the wife's alcoholism as a mistaken sacri- ㅇ ficial attempt by her to stop competing with her husband for control of their jointly owned busi- $z$ ness. She returned in three weeks formally relinquishing any further desire to work with her husband. 'I'll be his companion, but never again his business partner,' she said. The tension in the relationship eased and she entered an alcohe rehabilitation programme.

These clinical vignettes give a flavour of the way in which different therapists operate. Basically, family therapists effect change by altering context. But what sort of problem is amenable to help?

Family systems impinge on immunological $\frac{\Phi}{\varnothing}$ systems, hormonal systems, and central nervous $\vec{F}$ systems so that many acute and chronic illnesses, behavioural and mental disorders are influenced by the family. Therapy has been actively pursued in relation to illnesses as diverse as diabetes and schizophrenia. Family members suffering from cancer, cardiac disease and reproductive problems have been treated in family therapy settings. An important general text about the use of family 8 therapy in medicine $e^{5}$ provides an entry into the different diagnostic problems thought to benefit $ᄋ$ from family intervention as well as exploring arguments for the existence of a theory of family systems medicine, attempting to define the theory, reviewing the experimental evidence and identify- $\sigma$ ing issues and questions for future study.

\section{Family therapy in a community setting}

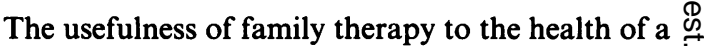
local community might be best shown by describ- 0 ing one family therapy clinic. The Prudence Skynner family therapy clinic established in 1983 within $\overparen{\Omega}$ Wandsworth District Health Authority treats 
families in which there are physically, mentally or emotionally ill adults. ${ }^{6}$ Administratively, the clinic is part of the specialist services of the Mental Health Unit. The clinic philosophy is that the family and the community have the capacity to help the ill adult; therefore the primary targets for change are the relationships between people. The professionals working in the clinics are from many disciplines including medical staff, social workers, psychologists and nurses. All therapists have access to modern supervisory techniques including videotape playback and one-way screen live supervision. Therapists tend to work in teams of four or more members. Family sessions last $1 \frac{1}{2}$ hours. The clinic has space for three teams per day and three families can be treated by each team during a working day. Specialist teams work respectively with families with a deaf member, families with an elderly infirm member and families with a learning disabled member.

The clinic is a multidisciplinary training facility and houses a trained family therapist as clinic coordinator. A two year postgraduate family therapy Diploma course is based in the clinic for those wishing a qualification. Other professionals wishing to train as family therapists are supervised in the clinic.

The clinic has treated a wide variety of family problems. Adults with alcoholism, drug addiction and psychoses have attended. Amputees, patients with spina bifida, bowel disorders, cancer and heart disease are present in families under treatment. Adults suffering from sexual abuse, and most of the neurotic disorders such as depression, anxiety states, obsessive-compulsive illness and hysterical disorders as well as eating disorders are part of the clinic's workload. Since family therapy aims to use family resources to help the sick individual, no diagnostic category need be excluded from the clinic.

\section{A clinical example of family therapy}

One detailed clinical example helps to illustrate the family therapy process. The following case is one of many families treated by the family therapy team for elderly persons.

\section{The team}

This team of professionals who work with elderly people in other settings felt that systems therapy would be a valuable method for assisting families where there is a problem in caring for an elderly relative. The team consists of a psychiatrist, a nurse, a social worker and a psychologist supervised by two experienced family therapists. Of 16 client families attending the clinic team, ten of the index clients have been over the age of 65 . The referrals come from social workers as well as medical practitioners. Six of the families have been attended at home but the majority come to the clinic. The reasons for referral are as follows, the most frequent listed first: depression, marital problems, mother-son problems, anxiety, eating/alcohol problems, unresolved grief, conflicts over future care and carer stress.

\section{Referral}

Mr Ted C took an overdose which led to his admission in January 1989. A previous treatment for depression in 1976 occurred after the death of his brother-in-law. He disliked the ward and was discharged home to attend the day hospital but remained withdrawn and miserable, and was readmitted after he slashed his wrists. $\mathrm{Mr} \mathrm{C}$ responded well to electroconvulsive therapy but remained agitated. The family were persuaded to accept a referral to the therapy team because Mrs $\mathrm{C}$ and her sister-in-law maintained that there was no reason at all for $\mathrm{Mr} \mathrm{C}$ to be depressed. They were angry that he had upset their lives by his behaviour. His daughter, Mrs $\mathbf{H}$, was worried that her father would become depressed again unless $\mathrm{Mrs} \mathrm{C}$ paid more attention to his needs for love and companionship.

\section{Family members}

Mr Edward C born 1915 (known as Ted) and Mrs Alma C born 1908 living in the ground floor flat. Mrs Louisa S, sister to Alma and sister-in-law to Ted, widowed and living in the first floor flat of the same house in South London. Mr and Mrs (Graham and Gwen) $\mathrm{H}$, son-in-law and daughter to Ted and Alma and living in Shropshire.

\section{Home circumstances}

Ted and Alma share a house with Louisa which they jointly own. They share some facilities and there has never been any structural separation of the two flats. Ted shared the job of upkeep and redecoration with Louisa's husband until his death in 1976. Louisa's flat is comfortably furnished but now needs decorative repair.

\section{Family history}

Ted was the youngest of five children, having two older brothers and two sisters. His father died before his birth and his mother placed the children in an orphanage where they were kept together. His mother remarried and all the children except Ted went to live with her. Ted re-established contact with his mother and stepfather in his early teens, and remained close to his siblings until his two brothers were apprenticed to a cobbler in Shrop- 
shire and eventually lost touch. He married Alma at 25 after a four year courtship. After leaving school Ted had several jobs, eventually becoming a foreman supervisor with a drug company. From 55 to 65 he was a dispatch manager with a London department store.

Alma is the youngest of two sisters. Her father died shortly after her birth but her mother managed to keep and care for the children by working as a tailoress. Alma has always been 'very close' to her older sister; both learned to sew to help their mother and worked as tailoresses until their marriages. They always had homes nearby each other. Louisa and her husband Sidney had no children and Alma moved in with her only daughter, Gwen, when Ted was away during the war.

Ted was active in a local senior citizen's club in retirement. Late in his life Ted had traced one of his older brothers but his two sisters had both committed suicide after being widowed.

\section{Family history}

Ted, Alma and Louisa attended five sessions during a four month period. Gwen and her husband attended the first session, forcefully putting their point that although Alma gives an impression of being warm and caring, she does not perceive or respond to Ted's needs, but give priority to Louisa who seemed the strongest and dominant personality in the septuagenarian triad. The team prescribed more time for Alma and Ted to spend together and separateness for Louisa. This prescription became a struggle for all of the participants in the therapy. The sisters returned to tell a story of Ted's motive for suicide. In 1988 Ted was found to have gall stones and an aortic aneurysm for which he required emergency surgery. This serious illness left Ted weak and led to an inward concern for his own health which became depressive, reinforced by his inability to do what he was previously able to do at home. Work by the therapists continued to be directed at trying to get Ted and Alma to act as a couple and spend must more time together, and separate from Louisa a little. They were encouraged to have a holiday by themselves either by visiting a resort or staying with Gwen.

The critical session and creation of a new reality came when the supervisor realized while sitting behind the one-way screen, that there was a strong $\mathbb{D}$ concern that Ted expressed about Louisa's health. The two sister's at first denied this worry was real, $\stackrel{\bullet}{\Rightarrow}$ but the team explored it and reinforced this view. Louisa, at 85 was increasingly frail, although 0 having a very forceful personality. She was the $\bar{E}$ 'matriarch' of this triangular system and her frailty $\frac{\bar{w}}{\partial}$ coupled with Ted's illness had shifted the balance in $ه$ the system. Recognition that Louisa needed the help of both Ted and Alma allowed the couple a joint role in caring for their septuagenarian 'child'. That Ted could offer help jointly with Alma was a $\overrightarrow{\vec{\omega}}$ difficult reality for the triad to accept and this new $\stackrel{\sigma}{\sigma}$ formulation had been obscured from the team for $\vec{C}$ three sessions. The team members struggled to 3 . create this new view for the sisters, aided by a more 8 commanding and forceful Ted. Eventually they 0 understood but only partially accepted the refram- or ed, redefined reality. But in the fifth session Ted 0 seemed well and cheerful again and had begun to pick up his old interests. Alma said that she appreciated the need to pay more attention to Ted $\rightarrow$ and spend more time with him. They all agree that $z$ 'things were now back to normal'. Louisa said $\overbrace{\Phi}$ gratefully, 'Ted brings me a cup of tea in the $\frac{\Im}{\square}$ morning now.'

\section{Follow-up}

Two years later this increasingly frail triad are we्]11 and functioning healthily. Ted is getting out on his own to the senior citizens club and the couple $\bar{O}$ continue to look after their ageing but well-loved 'child'.

\section{Conclusions}

Family therapy is a treatment of growing complex- $\bar{\partial}$ ity, maturity and applicability. A recent review of the current literature ${ }^{7}$ indicates that family systems remain a viable study area for clinical reports, research and theoretical studies. Family systems are increasingly being taken into account in the new

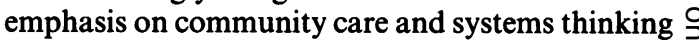
is beginning to shape national policy on health care delivery.

\section{References}

1. Pickle, W. Epidemiology in Country Practice. J. Wright and Son, Bristol, 1939.

2. Gurman, A., Kniskern, D. \& Pinsoff, W. Research on the process and outcome of marital and family therapy. In: Garfield, S. \& Bergin, A. (eds) Handbook of Psychotherapy and Behaviour Change, 3rd ed. Wiley, London, 1986, pp. 565-570.

3. Wynne, L. (ed.) State of the Art of Family Research. Family Process Press, New York, 1988.
4. Bobele, M. Interactional treatment of intractable hiccups. Fam Process 1990, 29: 191-206.

5. Ramsey, C.N. (ed.) Family Systems in Medicine. Guilford Press, London, 1989.

6. Lieberman, $S$. The birth pains of establishing a family therapy clinic in the NHS. Context 1989, 8-9.

7. Lieberman, S. Aspects of family therapy. Curr Opin Psychiat 1991, 4: 394-400. 